\title{
Efeito do gás ozônio na descontaminação de canetas de bisturi elétrico
}

Uma das principais preocupações na prestação da assistência à saúde está relacionada ao processamento dos produtos utilizados. Portanto, essa qualidade no processamento dos produtos só será efetiva, quando reduzir ou destruir a carga microbiana, mantendo sua funcionalidade e integridade. Assim sendo, o gás ozônio, conhecido pela sua ação antimicrobiana, surge como potencial alternativa para facilitar alguns mecanismos de esterilização de alguns instrumentais médico-hospitalares. Objetivou-se, nesta pesquisa, estimar a carga microbiana e avaliar a eficácia do gás ozônio na descontaminação de canetas de bisturi elétrico nos diferentes tempos de tratamento. Foram coletadas amostras das canetas de bisturi elétrico antes do tratamento com ozônio e 5,10 e 15 minutos após a exposição ao gás, e realizadas as culturas para bactérias e fungos em meios seletivos e não seletivos, sempre em triplicata. Os resultados foram avaliados por meio do teste de Kruskal-Wallis com posterior teste de comparação múltipla de Dunn. Os microrganismos isolados antes do tratamento foram: Staphylococcus aureus, Escherichia coli, Candida albicans, Proteus vulgaris, Micrococcus spp, Bacillus spp., Proteus mirabilis. Após a exposição ao gás ozônio, pôde-se observar que nos microorganismos Staphylococcus aureus, Micrococcus spp. e Bacillus spp., o ozônio promoveu a destruição dos microrganismos no tempo de 10 minutos. Na Escherichia coli, Proteus mirabilis e Proteus vulgaris essa morte aconteceu já na exposição a 5 minutos. 0 único microrganismo que necessitou de 15 minutos de exposição para ser eliminado totalmente foi a Candida albicans. Pode-se concluir que na metodologia adotada o gás ozônio foi eficiente na esterilização de canetas de bisturi elétrico, quando o tratamento se deu a 15 minutos de exposição.

Palavras-chave: Controle; Desinfecção; Segurança do Paciente.

\section{Effect of ozone gas on decontamination of electric scalpel pens}

One of the main concerns in health care delivery is related to the processing of the products used. Therefore, this quality in product processing will only be effective when reducing or destroying the microbial load, maintaining its functionality and integrity. Thus, ozone gas, known for its antimicrobial action, emerges as a potential alternative to facilitate some sterilization mechanisms of some medical-hospital instruments. The objective of this research was to estimate the microbia load and to evaluate the effectiveness of ozone gas in the decontamination of electric scalpel pens at different treatment times. Samples were taken from the electric scalpel pens before ozone treatment and 5, 10 and 15 minutes after exposure to gas, and cultures for bacteria and fungi were performed in selective and non-selective media, always in triplicate. Results were evaluated using the Kruskal-Wallis test with subsequent Dunn multiple comparison test. The microorganisms isolated before treatment were: Staphylococcus aureus, Escherichia coli, Candida albicans, Proteus vulgaris, Micrococcus spp., Bacillus spp., Proteus mirabilis. After exposure to ozone gas, it was observed that in the microorganisms Staphylococcus aureus, Micrococcus spp. and Bacillus spp., The ozone promoted the destruction of the microorganisms within 10 minutes. In Escherichia coli, Proteus mirabilis and Proteus vulgaris this death has already occurred in the 5 minutes exposure. The only microorganism that required 15 minutes of exposure to be completely eliminated was Candida albicans. It can be concluded that in the adopted methodology the ozone gas was efficient in the sterilization of electric scalpel pens, when the treatment occurred at 15 minutes of exposure.

Keywords: Control; Disinfection; Patient safety.

Topic: Epidemiologia e Saúde Ambiental

Reviewed anonymously in the process of blind peer.
Received: 09/06/2019

Approved: 11/07/2019
Taise Jordão Zanzarini (iD)

Centro Universitário de Santa Fé do Sul, Brasi

http://lattes.cnpq.br/3211950419210086

http://orcid.org/0000-0003-1567-1424

taisejord@hotmail.com

Dora Inés Kozusny-Andreani (it

Universidade Brasil, Brasil

http://lattes.cnpq.br/1260217332585007

http://orcid.org/0000-0003-3579-6419

doraines@terra.com.br

\section{Referencing this:}

ZANZARINI, T. J.; KOZUSNY-ANDREANI, D. I.. Efeito do gás ozônio na descontaminação de canetas de bisturi elétrico. Revista IberoAmericana de Ciências Ambientais, v.10, n.4, p.112-120, 2019. DOI: http://doi.org/10.6008/CBPC2179-6858.2019.004.0009 


\section{INTRODUÇÃO}

Uma das principais preocupações na prestação a assistência à saúde está relacionada a limpeza e a descontaminação dos equipamentos utilizados (SOUZA et al., 2011; ANVISA, 2013). Todo o equipamento clínico deve ser limpo e descontaminado antes e após o uso, independentemente de quantas vezes ele é usado, onde e como é usado. Um item destinado ao uso do paciente deve ser inspecionado cuidadosamente antes de ser empregado, e se a limpeza prévia não for evidente por notificação ou sujeira, ele deve ser imediatamente limpo de acordo com os protoclos disponíves na entidade de saúde (DANCER, 2014). Essa preocupação, quanto à promoção da segurança do paciente e a qualidade dos serviços prestados, também se respalda no manuseio dos artigos médicos, considerando que a maioria deles são reutilizados (RUTALA et al., 2013).

No âmbito hospitalar, existem equipamentos e utensílios que podem entrar em contato com sangue e/ou fluidos corporais, entre eles os oxímetros de pulso, estetoscópios, termômetros, kits para teste de glicose no sangue, sondas de saturação, aparelhos não descartáveis usados na higiene de pacientes, entre outros, os quais devem ser submetidos a procedimentos de limpeza e de desinfecção rigorosos antes e depois do uso com a finalidade de diminuir a carga microbiana, promovendo desta forma a segurança do paciente (ZACHARY, et al., 2001; DANCER, 2012). No entanto, é necessário que os agentes esterilizantes se adequem conforme os produtos submetidos a descontaminação, de modo que incidam na eficácia e rapidez do processamento (DANCER, 2014).

Os instrumentos hospitalares e dispositivos médicos são submetidos ao processo de esterilização para garantir a qualidade e segurança do produto. O processo de esterilização está associado a destruição e a eliminação das formas microbianas dos instrumentos e artigos médicos utilizados em quaisquer procedimentos realizados e podem ocorrer de maneira química ou física (RUTALA et al., 2013). A aplicação de métodos convencionais de esterilização, como o uso de alta temperatura, alta pressão, gás químico e radiação (raios gama), depende do tipo de material a ser esterilizado (FITRIA et al., 2019). Nos últimos anos, verificou-se a busca contínua por tecnologias de esterilização em baixas temperaturas à baixa temperatura, que incluem: óxido de etileno, radiação gama, plasmas de peróxido de hidrogênio e o ozônio $\left(\mathrm{O}_{3}\right)$, entre outros (SOUZA et al., 2011; OLIVEIRA et al., 2012; GALANTE et al., 2017, GONZAGA et al., 2018; FITRIA et al., 2019).

O gás ozônio $\left(\mathrm{O}_{3}\right)$ é um gás natural que se origina da transformação do oxigênio, em que é acrescido uma molécula ( $\mathrm{BOCCl}$ et al., 2015). O ozônio pode ser considerado o germicida natural mais potente contra microrganismos (nas formas vegetativa e esporuladas) com alta eficiência e velocidade, devido à sua atividade altamente oxidante (BOTELHO-ALMEIDA et al., 2018). Essa característica torna-se benéfica em diversas áreas da saúde, desde a ozonioterapia até a descontaminação dos ambientes e dos resíduos, trazendo assim várias vantagens no gerenciamento de qualidade e do bem-estar do paciente ( $\mathrm{AVCl}$ et al., 2015; KOZUSNY-ANDREANI et al., 2018; GONZAGA et al., 2018). 
A descontaminação de artigos médicos, por meio do $\mathrm{O}_{3}$, faz com que seja estabelecida uma pressão negativa na câmara de esterilização, onde a água, a eletricidade e o oxigênio acabam gerando o gás ozônio, que é utilizado para esterilizar artigos e materiais que são sensíveis a umidade e ao calor (SLAVISH, 2012). No Brasil, um dos dispositivos mais reutilizados é a caneta de bisturi elétrico que é indicada para cirurgias tanto de porte pequeno quanto grande (BATISTA NETO et al., 2010). Por conta disso, é indicado que as Centrais de Materiais de Esterilização (CME) dos hospitais observem os procedimentos a serem seguidos para que a esterilização ocorra de maneira efetiva (WANI et al., 2015) Neste contexto objetivou-se nesta pesquisa estimar a carga microbiana e avaliar a eficácia do gás ozônio na descontaminação de canetas de bisturi elétrico em diferentes tempos de exposição.

\section{MATERIAIS E MÉTODOS}

Foram avaliadas canetas de bisturis elétricos, após sua utilização em um centro cirúrgico onde são realizadas intervenções de pequeno porte (cirurgias urológicas, dermatológicas e gerais), oferecidas em um Ambulatório Médico de Especialidades do Noroeste Paulista. Os tratamentos foram: canetas de bisturis elétricos não lavadas, e canetas submetidas a tratamento com gás ozônio por 5, 10 e 15 minutos. Para a realização dos testes de desinfecção cada uma das canetas foi submetida à ozonização com dose de 140, 280, $420 \mathrm{mg} \mathrm{L}^{-1}$ de ozônio.

O ozônio foi obtido por um equipamento gerador corona, Modelo Ozone \& Life ${ }^{\circledR}$ (Medical System), sendo a concentração do gás limitada pelo equipamento, calibrado em uma vazão de $\mathrm{O}_{3}$ de $28 \mathrm{mg} \cdot \mathrm{L}^{-1}$. O fluxo de entrada do gás oxigênio $\left(\mathrm{O}_{2}\right)$ utilizado foi de $1 \mathrm{~L}$ por minuto de $\mathrm{O}_{2}$ e a temperatura do ambiente controlada a $20^{\circ} \mathrm{C}$ durante todo o experimento. $\mathrm{O}$ gás ozônio foi conduzido ao recipiente de ozonização por meio de um tubo de silicone.

Foi utilizado um sistema de fumigação de ozônio modificado, proposto por Gonzaga et al. (2018). O processo de ozonização foi realizado em câmara de vidro, projetada para melhorar a aplicação de ozônio nas superfícies a serem desinfetadas e para reduzir o tempo necessário para atingir as concentrações de ozônio desejadas no interior da mesma. A câmara usada na ozonização foi confeccionada em formato retangular, com dimensões de $25,5 \times 25,0 \times 15,3 \mathrm{~cm}$ (volume $9,753 \mathrm{~cm}^{3}$ ou 9,753L).

Para iniciar o processo de ozonização, a câmara foi fechada na parte superior com uma tampa móvel para inserção e retirada do material. Nas extremidades foram colocados orifícios que permitissem a entrada e saída do gás. Cada caneta foi colocada no interior da câmara e exposta ao ozônio uma vez que a concentração desejada foi atingida. Finalizado cada período de ozonização foram retiradas amostras da superfície da caneta de bisturi tratado para a realização das análises microbiológicas, utilizando-se swabs umedecidos em solução salina e friccionados na superfície, e depositados em tubos contendo $10 \mathrm{~mL}$ de solução de $\mathrm{NaCl}(0,5 \%)$ estéril.

Para avaliação da eficácia do processo de desinfecção foi utilizada a metodologia descrita por Gonzaga et al. (2018). Os meios utilizados para o cultivo do material coletado dos bisturis elétricos antes e após ozonização, foram o Ágar Sabouraud-dextrose, Ágar triptecaseína-soja, Ágar Baird Parker e Ágar 
Cetrimide. Os meios inoculados para isolamento de bactérias foram incubados a $37^{\circ} \mathrm{C}$ por $24-48 \mathrm{~h}$, enquanto a cultura para fungos foi conduzida por 15 dias em temperatura de $25^{\circ} \mathrm{C}$. Transcorridos os períodos de incubação, procedeu-se a contagem de unidades formadoras de colônias (UFC) e identificação dos microorganismos presentes em cada uma das placas. Para se realizar as coletas dos materiais para análise das canetas de bisturis elétricos, utilizou-se o fluxo laminar e equipamentos de proteção individual.

As bactérias e os fungos isolados foram caracterizados, respectivamente, pela Coloração de Gram e pelo Azul de Algodão e identificados por métodos bioquímicos, de acordo com a metodologia descrita por Winn et al. (2008). Para a identificação das espécies bacterianas Gram-negativas foi utilizado o sistema API 20E (Analytical Profile Index, BioMérieux) e para a caracterização das espécies bacterianas Gram-positivas foram realizados os testes: catalase, coagulase, DNAse, oxidase e hemólise. Todos os experimentos para as análises microbiológicas, tanto das amostras coletadas das canetas de bisturi antes do tratamento quanto para as amostras tratadas, foram realizados em triplicata.

Para a avaliação da eficácia do efeito antimicrobiano de cada um dos tratamentos com ozônio, um estudo sobre a variação da carga microbiana foi realizado a fim de observar qual tratamento apresentou a maior variação negativa (queda) na contagem microbiana. Nesse contexto, a variação percentual da contagem microbiana consistiu da seguinte relação: $\operatorname{Variação~}_{\text {contagem microbiana }}(\%)=$ $\frac{\left(\text { Contagem }_{5 \mathrm{mi}}-\text { Contage }_{\mathrm{omin}}\right)}{\text { Contagem }_{0 \mathrm{mi}}} \times 100$. De acordo com a expressão, variações negativas mostram diminuição na contagem microbiana e variações positivas mostram aumento da contagem microbiana à medida que o tempo de exposição aumenta.

Os resultados foram avaliados pelo teste de Kruskal-Wallis, com posterior teste de comparação múltipla de Dunn para comparar a contagem microbiana dos mesófilos totais em relação aos tratamentos com ozônio. Análise descritiva percentual da ocorrência de diferentes micro-organismos de acordo com os trata mentos empregados. Todos os testes estatísticos foram aplicados com nível de significância de 5\% $(P<0,05)$.

\section{RESULTADOS E DISCUSSÃO}

Em um primeiro momento foi realizado um estudo da contagem de mesófilos totais em bisturis elétricos submetidos a tratamentos com ozônio com a finalidade de observar ação desse agente de desinfecção. As amostras foram avaliadas antes e depois de serem submetidas ao ozônio, em intervalos diferenciados, sendo eles: 5 minutos, 10 minutos e 15 minutos. Na tabela 1, estão evidenciadas as estatísticas descritivas da contagem microbiana dos bisturis elétricos de acordo com os tratamentos empregados. Verificou-se que houve diferenças significativas entre as contagens microbianas quando os tratamentos foram comparados $(p<0,001)$.

Foi possível observar que a contagem dos mesófilos totais foi superior para o tratamento sem ozonização e, a partir que os bisturis foram submetidos a tempos diferenciados de ozonização, a contagem dos mesófilos totais foi decrescendo de forma significativa. A presença de um número relativamente elevado 
de microrganismos nas canetas de bisturi elétrico (tabela 1 ) estão relacionadas a capacidade dos microrganismos em colonizarem superfícies abióticas ou tecidos animais e vegetais.

Tabela 1: Contagem de mesófilos totais presentes em canetas de bisturis elétricos antes e após a utilização do gás ozônio.

\begin{tabular}{|l|l|l|l|}
\hline Tratamento & Média \pm desvio padrão & Mediana & $($ Mín; Máx) \\
\hline Sem ozônio & $5,9.10^{3} \pm 1,4.10^{4}$ & $3,0.10^{2} \mathrm{a}$ & $\left(1,3.10^{2} ; 4,4.10^{4}\right)$ \\
\hline Ozônio por 5 minutos & $8,3.10^{1} \pm 1,3.10^{2}$ & $2,9.10^{1} \mathrm{~b}$ & $\left(1,0.10^{0} ; 5,0.10^{2}\right)$ \\
\hline Ozônio por 10 minutos & $1,8.10^{1} \pm 4,2.10^{1}$ & $2,5.10^{0} \mathrm{c}$ & $\left(1,0.10^{0} ; 1,6.10^{2}\right)$ \\
\hline Ozônio por 15 minutos & $0,0 \pm 0,0$ & $0,0 \mathrm{~d}$ & $(0,0 ; 0,0)$ \\
\hline Valor $\mathrm{p}^{1}$ & \multicolumn{2}{|c|}{$<0,001$} \\
\hline
\end{tabular}

Legenda: ${ }^{1}$ Valor $\mathrm{P}$ referente ao teste de Kruskal-Wallis a $\mathrm{P}<0,05 ;{ }^{2}$ Letras diferentes na mesma coluna diferenciam-se entre si pelo teste de comparação múltipla de Dunn a $P<0,05$.

A colonização de dispositivos médicos e a formação de biofilmes na sua superfície podem desencadear infecções graves principalmente em humanos com deficiência de sistema imunológico. $\mathrm{Na}$ atualidade são empregados vários métodos para a prevenção da formação de biofilmes microbianos, ainda assim, uma vez que um biofilme é formado, sua eliminação requer a utilização de métodos mais apurados, tais como: plasma a frio, ultrassom, laser, tratamento com água ozonizada, gás ozônio entre outros (CANADÁ et al., 2014; ZABIELSKA et al., 2016).

Após o tratamento das canetas com ozônio, verificou-se que foram necessários 15 minutos de exposição das amostras ao gás para comprovar a ausência total de mesófilos totais nas amostras avaliadas (tabela 1). Segundo Brodowska et al. (2017) e Kozusny-Andreani et al. (2018), após o tratamento com ozônio, a taxa de sobrevivência dos micro-organismos diminui drasticamente, evidenciando que a eficiência do tratamento com ozônio depende do tempo de contato com o gás e da dose.

Os dados da tabela 2 indicam diferenças estatisticamente significativas na taxa de sobrevivência dos mesófilos totais. A variação nos primeiros 5 minutos de exposição foi relevante, apresentando redução de $96,5 \%$ na contagem dos mesófilos totais nos bisturis elétricos, pressupondo que os primeiros cinco minutos de exposição já são suficientes para que a contagem microbiana dos mesófilos totais apresente uma redução significante. Desse modo, o tratamento com ozônio a 15 minutos é o mais eficaz no objetivo de desinfecção dos bisturis elétricos, já que nesse tempo de exposição ocorreu contagem microbiana nula.

Tabela 2. Variação percentual (\%) da contagem taxa de sobrevivência dos mesófilos totais em canetas de bisturis elétricos antes e após a utilização do gás ozônio.

\begin{tabular}{|l|l|l|}
\hline \multirow{2}{*}{ Tempos de exposição ao ozônio } & \multicolumn{2}{|c|}{ Variação da contagem microbiana (\%) } \\
\cline { 2 - 3 } & Média \pm desvio padrão & $-96,5 \mathrm{~b}$ \\
\hline 0 a $5 \mathrm{~min}$ & $-89,4 \pm 14,0$ & $-81,5 \mathrm{a}$ \\
\hline 5 a $10 \mathrm{~min}$ & $-70,8 \pm 39,4$ & $-100 \mathrm{c}$ \\
\hline 10 a $15 \mathrm{~min}$ & $-100 \pm 0,0$ & $<0,001$ \\
\hline Valor $\mathrm{P}^{1}$ & & \\
\hline
\end{tabular}

Legenda: ${ }^{1}$ Valor $\mathrm{P}$ referente ao teste de Kruskal-Wallis a $\mathrm{P}<0,05 ;{ }^{2}$ Letras diferentes na mesma coluna diferenciam-se entre si pelo teste de comparação múltipla de Dunn a $\mathrm{P}<0,05$.

Resultados semelhantes foram observados por Brodowski et al. (2017), em estudo para o desenvolvimento de um modelo de tratamento de vários microrganismos com diferentes doses de ozônio e de tempos de contato. Os resultados indicaram que o aumento da concentração de ozônio e o tempo de contato aumentaram as taxas de redução na carga microbiana. Brodowski et al. (2017) afirma que as células 
que sobrevivem tornam-se mais resistentes ao ozônio e que a eficácia do tratamento com ozônio diminui com o tempo. Isso significa que um maior tempo de contato com o ozônio pode ter um impacto negativo na qualidade do produto sob a perspectiva microbiológica, causando maior resistência ao ozônio e à reativação.

Devido à sua meia vida curta, sua toxicidade e reatividade, o gás ozônio deve ser produzido no local. O ozônio reage mais lentamente com ácidos graxos e carboidratos, e mais rapidamente com proteínas, aminas, aminoácidos, ácidos nucleicos e grupos funcionais de proteínas (ROSENBLUM et al., 2012). Assim a fumigação de materiais com gás ozônio pode constituir um sistema antimicrobiano alternativo eficaz, uma vez que é capaz de penetrar em todas as irregularidades superficiais e é aplicável a um amplo espectro microbiano (MARTINS et al., 2015; MARTINELLI et al., 2017).

A tabela 3 evidencia os percentuais de ocorrência de diversos micro-organismos isolados nos bisturis elétricos de acordo com o tempo de exposição dessas amostras ao ozônio. Constatou-se que a partir do momento que o tempo de exposição ao ozônio foi aumentando, o número de ocorrências e, a variedade de microrganismos foi diminuindo de forma drástica até culminar na total eliminação com 15 minutos de exposição ao ozônio. De acordo com os resultados obtidos é possível observar que o tratamento sem ozônio apresentou maior quantidade e a maior diversidade de micro-organismos quando comparados aos demais tratamentos. A partir do momento que a exposição ao ozônio foi aumentando, o número de ocorrências e, a variedade de microrganismos foi diminuindo de forma drástica até culminar na total supressão dos microorganismos avaliados a 15 minutos de exposição ao ozônio.

Tabela 3. Ocorrência dos micro-organismos encontrados nos em canetas de bisturis elétricos antes e após a utilização do gás ozônio.

\begin{tabular}{|l|l|l|l|l|}
\hline Microrganismos & Sem ozônio & $5 \min$ & $10 \mathrm{~min}$ & $15 \mathrm{~min}$ \\
\hline Staphylococcus aureus & $3(50,0 \%)$ & $3(50,0 \%)$ & $0(0,0 \%)$ & $0(0,0 \%)$ \\
\hline Escherichia coli & $5(100 \%)$ & $0(0,0 \%)$ & $0(0,0 \%)$ & $0(0,0 \%)$ \\
\hline Candida albicans & $6(33,3 \%)$ & $6(33,3 \%)$ & $6(33,3 \%)$ & 0 \\
\hline Proteus vulgaris & $2(100 \%)$ & $0(0,0 \%)$ & $0(0,0 \%)$ & $0,0 \%)$ \\
\hline Micrococcus spp. & $3(50,0 \%)$ & $3(50,0 \%)$ & $0(0,0 \%)$ & $0(0,0 \%)$ \\
\hline Bacillus spp. & $2(50,0 \%)$ & $2(50,0 \%)$ & $0(0,0 \%)$ & $0(0,0 \%)$ \\
\hline Proteus mirabilis & $1(100 \%)$ & $0(0,0 \%)$ & $0(0,0 \%)$ & $0(0,0 \%)$ \\
\hline Total & 22 & 14 & $6(0,0 \%)$ & 0 \\
\hline
\end{tabular}

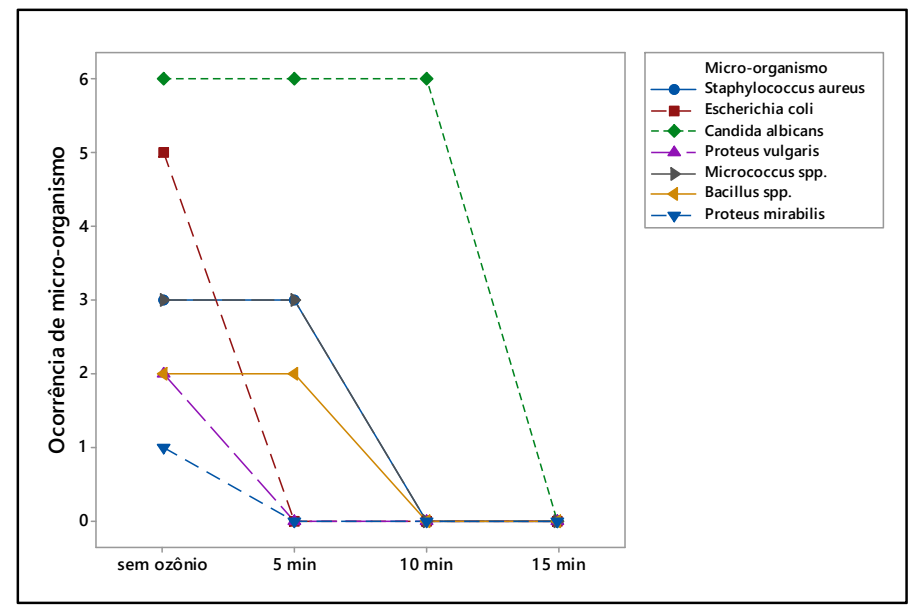

Figura 1. Taxa de sobrevivência das espécies microbianas isoladas em canetas de bisturis elétricos antes e após a utilização do gás ozônio. 
Verificou-se que Escherichia coli e Proteus spp apresentaram maior sensibilidade ao ozônio, visto que com apenas 5 minutos de exposição a contagem foi nula enquanto para Staphylococcus, Micrococcus e Bacillus foram necessários 10 minutos. Em contrapartida, a levedura Candida albicans exibiu maior resistência ao tratamento com ozônio e somente verificou-se ocorrência nula aos 15 minutos de exposição ao agente desinfetante (figura 1). O ozônio tem efeito bactericida sobre bactérias Gram-positivas e Gramnegativas, sendo este efeito proporcional à concentração, ao tempo de exposição e a espécie bacteriana (TORMIN et al., 2016; KOZUSNY-ANDREANI et al., 2018).

Atualmente, não há dúvidas quanto à capacidade bactericida, fungicida, virucida do ozônio, no entanto o uso do ozônio requer alguns cuidados, pois é um gás extremamente tóxico em concentrações elevadas (SOUZA et al., 2011). O ozônio possui produtos de decomposição que podem rapidamente inativar microrganismos (por exemplo, radical hidróxila) por reação com enzimas intracelulares, material nucléico e componentes da parede celular. A inativação de bactérias usando ozônio causa vazamento de conteúdo interno devido à oxidação de lipídios insaturados na parede célular, que finalmente resulta em lise celular (KHADRE et al., 2001, DAKA et al., 2012, KANAAN, 2018)

A descontaminação e esterilização com ozônio apresenta vantagens substanciais, o gás pode penetrar efetivamente nos objetos, incluindo locais para os quais o acesso é difícil usando líquidos convencionais e procedimentos de limpeza manual. O ozônio é conhecido por ter atividade antibacteriana, pode ser gerado de forma barata, e, embora tóxico em altas concentrações, dissocia-se rapidamente ao oxigênio, com uma meia-vida de cerca de 20 minutos (SHARMA et al., 2008). Por esta razão ao decidir aplicar um método de descontaminação com gás ozônio, é necessário saber sobre qual a relação da concentração de gás a ser alcançada e a capacidade de difusão do ozônio, entre carga microbiana e o tempo, para que se possa definir sua capacidade como esterilizante ou desinfetante (CHRIST et al., 2017).

A crescente utilização do gás ozônio como um agente antimicrobiano está relacionada a sua alta eficiência antimicrobiana, e seu emprego está de acordo com os requisitos ambientais. Outros aspectos importantes que devem ser considerados são a necessidade de utilizar tecnologias mais verdes e métodos mais seguros de descontaminação e esterilização (DANCER, 2014; GALANTE et al., 2017, BORRELLI et al., 2018). De acordo com Ridiquieri et al. (2016), o uso do esterilizador de ozônio se torna uma opção interessante, pois utiliza uma matéria-prima natural (oxigênio), funciona a baixas temperaturas, baixo custo e, apesar da toxicidade do ozônio, rapidamente se decompõe em oxigênio.

\section{CONCLUSÕES}

Frente aos resultados encontrados, é possível concluir que o gás ozônio apresentou-se eficiente na descontaminação de canetas de bisturi elétrico, quando tratados no tempo de 15 minutos, contra todos os micro-organismos previamente isolados, independentemente de sua carga microbiana, sendo de 10 minutos para bactérias e 15 minutos para leveduras. A implementação de um sistema de descontaminação ou de esterilização que utilize ozônio como agente antimicrobiano seria relevante do ponto vista da segurança do paciente e econômico para as instituições que prestam assistência à saúde. 


\section{REFERÊNCIAS}

ANVISA. Agência Nacional de Vigilância Sanitária (Brasil). Resolução n.36 de $\mathbf{2 5}$ de julho de 2013. Institui ações para a segurança do paciente em serviços de saúde e dá outras providências. BRASÍLIA: ANVISA, 2013.

AVCI, S.; BUYUKCAM, F.; DEMIR, O. F.. Anton syndrome during oxygen-ozone therapy. American Journal of Emergency Medicine, Virginia, v.33, 2015. DOI: http://doi.org/10.1016/j.ajem.2014.11.041

BATISTA NETO, S. B.; GRAZIANO, K. U.; PADOVEZE, M. C.; KAWAGOE, J. Y.. Eficácia da esterilização de canetas de bisturi elétrico de uso único reprocessadas. Revista LatinoAmericana de Enfermagem, Ribeirão Preto, v.18, n.1, p.8186, 2010.

BOCCI, V.; ZANARDI, A. I.; VALACCHIB, G.; BORRELLI, E.; TRAVAGLI, V.. Validity of oxygen-ozone therapy as integrated medication form in chronic inflammatory diseases. Cardiovascular \& Haematological Disorders-Drug Targets, v.15, n.2, p.127-138, 2015. DOI: http://doi.org/10.2174/1871529X150215120911464

BORRELLI, E.; BOCCl, V.. The Use of Ozone in Medicine. Annals of Medical and Health Sciences Research, v.8, p.117119, 2018.

BOTELHO-ALMEIDA, T. S.; LOURENÇO, F. R.; KIKUCHI, I. S.; AWASTHI, R.; DUA, K.; PINTO, T. J. A.. Evaluating the potential, applicability, and effectiveness of ozone sterilization process for medical devices. Journal of Pharmaceutical Innovation, v.13, n.2, p.87-94, 2018. DOI: https://doi.org/10.1007/s12247-017-9308-7

BRODOWSKA, A. J.; NOWAK, A.; KONDRATIUK-JANYSKA, A.; PIATKOWSKI, M.; SMIGIELSKI, K.. Modelling the ozone-based treatments for inactivation of microorganisms. International Journal of Environmental Research and Public Health, v.14, n.10, p.1-15, 2017. DOI:

https://doi.org/10.3390/ijerph14101196

CHRIST, D.; SAVI, G. D.; SCUSSEL, V. M.. Effectiveness of Ozone Gas Application Methods against Combined MultiContaminants in Food. Food and Public Health, Oxford, v.7, n.3, p.51-58, 2017. DOI:

https://doi.org/10.5923/i.fph.20170703.01

DAKA, D.; SILASSIE, S.; YIHDEGO, D.. Antibiotic-resistance Staphylococcus aureus isolated from cow's milk in the Hawassa area, South Ethiopia. Annals of Clinical Microbiology and Antimicrobials, v.11, n.26, p.1-6, 2012.

DANCER, S. J.. Infection control 'undercover': a patient experience. Journal of Hospital Infection, v.80 p.189-191, 2012. DOI: https://doi.org/10.1016/j.jhin.2011.12.003

DANCER, S. J.. Controlling hospital-acquired infection: focus on the role of the environment and new technologies for decontamination. Clinical Microbiology Reviews, v.27, p.665-690, 2014.

FITRIA, S.; BUNTAT, Z.; NAWAWI, Z.; BAKAR SIDIK, M. I.; YUNIARTI, J. D.. Antibacterial potency of ozonated water against Escherichia coli. Journal of Pure and Applied
Microbiology, v.13, n.1, p.637-641, 2019. DOI: https://doi.org/0.22207/JPAM.13.1.73

GALANTE, R.; GHISLENI, D.; PARADISO, P.; ALVES, V. D.; PINTO, T. J. A.; COLAÇO, R.. Sterilization of silicone-based hydrogels for biomedical application using ozone gas: comparison with conventional techniques. Materials Science \& Engineering C-Materials for Biological Applications, Oxford, v.78, p.389-397, 2017. DOI: https://doi.org/10.1016/j.msec.2017.04.073

GONZAGA, T. N.; KOZUSNY-ANDREANI, D. I.. Utilização de gás ozônio na desinfecção de resíduos de serviços de saúde. Revista Interdisciplinar de Estudos da Saúde, Caçador, v.7, n.2, p.125-139, 2018.

DOI: http://doi.org/10.33362/ries.v7i2.1428

KANAAN, M. H. G.. Antibacterial effect of ozonated water against methicillin-resistant Staphylococcus aureus contaminating chicken meat in Wasit Province, Iraq. Veterinary World, v.11, n.10, p.1445-1453, 2018. DOI: http://doi.org/10.14202/vetworld.2018.1445-1453

KHADRE, M. A.; YOUSEF, A. E.; KIM, J. G.. Microbiological aspects of ozone applications in food: A review. Journal of Food Science, Chicago, v.66, n.9, p.1242-1252, 2001.

KOZUSNY-ANDREANI, D. I.; ANDREANI, G.; PRADO, L. F. A.; SPAZIANI, A. O.; KAIRALA, R. C. O. M.; SILVA, F. S.; ZANGARO, R. A.. In vitro inactivation of pathogenic bacteria by the use of ozone in different exposure times. Revista Cubana de Medicina Tropical, Habana, v.70, n.1, p.34-44, 2018.

MARTINELLI, M.; GIOVANNANGELI, F.; ROTUNNO, S.; TROMBETTA, C. M.; MONTOMOLI, E.. Water and air ozone treatment as an alternative sanitizing technology. Journal of Preventive Medicine and Hygiene, v.58, n.1, 2017.

MARTINS, C. C.; KOZUSNY-ANDREANI, D. I.; MENDES, E. C. B. Ozônio no controle de micro-organismos em resíduos de serviços de saúde. Revista Baiana de Enfermagem, Salvador, v.29, n.4, p.318-327, 2015. DOI:

http://doi.org/10.18471/rbe.v29i4.13678

OLIVEIRA, D. C.; KIKUCHI, I. S.; MOREIRA, A. J.; SILVA, J. M. F.; MANSANO, R. F.; PINTO, T. J. A.. Evaluation of microbiocidal activity of oxygen containing plasma using biological monitors with different lumen calibers. Acta Farmacéutica Bonaerense, Buenos Aires, v.3. n.1, p.257-264, 2012.

RIDIQUIERI, C. F.; PINTO, T. J. A.; BOU-CHACRA, N. A.; GALANTE, R.; ARAÚJO, G. L.; PEDROSA, T. N. Ozone gas as a benign sterilization treatment for PLGA nanofiber scaffolds. Tissue Engineering Part C: Methods, v.22, n.4, p.338-347, 2016. DOI: https://doi.org/10.1089/ten.tec.2015.0298

ROSEMBLUM, J.; GE, C.; BOHREROVA, Z.; YOUSEF, A.; LEE, J.. Ozonation as a clean technology for fresh produce industry and environment: sanitizer efficiency and wastewater quality. Journal of Applied Microbiology, v.113, n.4, p.837845, 2012. DOI: http://doi.org/10.1111/j.13652672.2012.05393.x

RUTALA, W. A.; WEBER, D. J.. Disinfection and sterilization: An overview. American Journal of Infection Control, v.41, 
p.52-55, 2013. DOl:

http://doi.org/10.1016/i.ajem.2014.11.041

SLAVISH, S. M.. Manual de Prevenção e Controle de Infecções para Hospitais. Porto Alegre: Artmed, 2012.

SHARMA, M.; HUDSON, J. B.. Ozone gas is an effective and practical antibacterial agent. Applied Epidemiology in Health Care Settings and the Community, Vancouver, v.36 n.8, p.559-563, 2008. DOI:

https://doi.org/10..1016/i.ajic.2007/10.021

SOUSA, C. S.; TORRES, L. M.; AZEVEDO, M. P. F.; CAMARGO, T. C.; GRAZIANO, K. U.; LACERDA, R. A.; TURRINI, R. N. T. Ozônio na esterilização de produtos para assistência à saúde: revisão integrativa da literatura. Revista da Escola de Enfermagem da USP, São Paulo, v.45, n.5, p.1243-1249, 2011.

TORMIN, S. C.; NAVARINI, A.; ALMEIDA, J. O. C. F.; TRAVASSOS, L. H. R.; NEGRI, M. V. G.; SILVA, R. A.. Análise do efeito bactericida do ozônio sobre bactérias multirressistentes. Arquivos médicos dos Hospitais e da Faculdade de Ciências Médicas Santa Casa São Paulo, São Paulo, v.61, p.138-141, 2016.
WANI, S.; MAKER, J, K.; THOMPSON, J. R.; BARNES, J.; SINGLETON, I.. Effect of Ozone Treatment on Inactivation of Escherichia coli and Listeria sp. on Spinach. Agriculture, Basel, v.5, p.155-169, 2015. DOI:

https://doi.org/10.3390/agriculture5020155

WINN, W.; ALLEN, S.; JANDA, W.; KONEMAN, E.; PROCOP, G.; SCHRECKENBERGER, P.; WOODS, G.. Koneman's color atlas and textbook of diagnostic microbiology. Baltimore: Lippincott Williams \& Wilkins, 2008.

ZABIELSKA, J.; TYFA, A.; KUNICKA-STYCZYŃSKA, A.. Methods for eradication of the biofilms formed by opportunistic pathogens using novel techniques - A review. Folia Biologica et Oecologica, tódź, v.12, n.1, p.26-36, 2016. DOI: http://doi.org/10.1515/fobio-2016-0003

ZACHARY, K. C.; BAYNE, P. S.; MORRISON, V. J.; FORD, D. S.; SILVER, L. C.; HOOPER, D. C.. Contamination of gowns, gloves, and stethoscopes with vancomycin-resistant enterococci. Infection Control \& Hospital Epidemiology, v.22, n.9, p.560-564, 2001. DOI: http://doi.org/10.1086/501952 